\title{
Prevalence, quantitative load and genetic diversity of Campylobacter spp. in dairy cattle herds in Lithuania
}

Sigita Ramonaitè ${ }^{1 *}$, Anita Rokaitytè ${ }^{1}$, Eglè Tamulevičiené ${ }^{2}$, Alvydas Malakauskas ${ }^{3}$, Thomas Alter ${ }^{4}$ and Mindaugas Malakauskas ${ }^{1}$

\begin{abstract}
Background: Campylobacteriosis is a zoonotic disease, and animals such as poultry, pigs and cattle may act as reservoirs for Campylobacter spp. Cattle shed Campylobacter spp. into the environment and they can act as a reservoir for human infection directly via contact with cattle or their faeces or indirectly by consumption of contaminated food. The aim of this study was to determine the prevalence, the quantitative load and the genetic strain diversity of Campylobacter spp. in dairy cattle of different age groups.

Results: Faecal samples of 200 dairy cattle from three farms in the central part of Lithuania were collected and examined for Campylobacter. Cattle herds of all three farms were Campylobacter spp. positive, with a prevalence ranging from $75 \%$ (farm I), 77.5\% (farm II) to 83.3\% (farm III). Overall, the highest prevalence was detected in calves (86.5\%) and heifers (86.2\%). In contrast, the lowest Campylobacter prevalence was detectable in dairy cows (60.6\%). C. jejuni, C. coli, C. lari and C. fetus subsp. fetus were identified in faecal samples of dairy cattle. C. upsaliensis was not detectable in any sample. The high counts of Campylobacter spp. were observed in faecal material of dairy cattle (average $4.5 \log _{10} \mathrm{cfu} / \mathrm{g}$ ). The highest numbers of Campylobacter spp. were found in faecal samples from calves (average $5.3 \log _{10} \mathrm{cfu} / \mathrm{g}$ ), whereas, faecal samples from cows harboured the lowest number of Campylobacter spp. (average $3.7 \log _{10} \mathrm{cfu} / \mathrm{g}$ ). Genotyping by flaA PCR-RFLP analysis of selected C. jejuni isolates showed that some genotypes were present in all farms and all age groups. However, farm or age specific genotypes were also identified.

Conclusions: Future studies are needed to investigate risk factors related to the degree of colonisation in cattle. Based on that, possible measures to reduce the colonisation and subsequent shedding of Campylobacter in cattle could be established. It is important to further investigate the epidemiology of Campylobacter in the cattle population in order to assess associated risks to public health.
\end{abstract}

Keywords: Calves, Heifers, Cows, Campylobacter spp, Prevalence, Genetic diversity

\section{Background}

Campylobacters are generally regarded as the most common bacterial cause of human gastroenteritis worldwide $[1,2]$ and the species C. jejuni is responsible for $80 \%$ to 93.4\% of the human campylobacteriosis cases depending on different geographic areas $[3,4]$.

Several studies revealed that ruminants may play an important role in the epidemiology of this zoonosis $[5,6]$.

\footnotetext{
* Correspondence: ramonaite@lva.lt

'Department of Food Safety and Quality, Faculty of Veterinary Medicine, Veterinary Academy, Lithuanian University of Health Sciences, Tilzes 18, Kaunas LT-47181, Lithuania

Full list of author information is available at the end of the article
}

Source attribution models attributed between $18 \%$-38\% of clinical strains or human cases to ruminant sources $[7,8]$. This is not surprising since up to $80 \%$ of cattle herds and $40-60 \%$ of the individual animals can shed Campylobacter spp. bacteria [9-11]. Despite the fact that consumption of contaminated poultry meat is assumed to be one of the most common cause of human campylobacteriosis [2], C. jejuni is frequently isolated from cattle of different ages as asymptomatic carriers of this pathogenic bacteria [9,12-14]. Proper application of biosecurity measures can lead to reduced colonization in poultry. However, biosecurity measures alone cannot to solve the problem. So far

\section{Biomed Central}

(c) 2013 Ramonaite et al.; licensee BioMed Central Ltd. This is an open access article distributed under the terms of the Creative Commons Attribution License (http://creativecommons.org/licenses/by/2.0), which permits unrestricted use, distribution, and reproduction in any medium, provided the original work is properly cited. 
no intervention measure is available to effectively eradicate, prevent or reduce Campylobacter colonisation in primary animal production chain, including broiler production $[15,16]$.

The humans could be infected with campylobacter from eating or drinking contaminated food, water, unpasteurized or raw milk or from close contact with infected animals. The consumption of unpasteurized milk has been the most important source of campylobacteriosis outbreaks [17]. Longer life span of dairy cattle than beef cattle can lead to permanent or long-term shedding of campylobacters by dairy cattle and these cattle serve as a long-term reservoir [18]. In addition, indirect exposure to cattle faeces through environmental contamination is considered a high risk to humans [19-21]. Up to now, there is limited and controversial information on the influence of the age of cattle on the Campylobacter prevalence [6,12,14,22,23].

Consequently, the role of different age groups of cattle from dairy farms as reservoir of Campylobacter spp. might be important for understanding the epidemiology of these pathogens.

The aim of this study was to evaluate the prevalence, the quantitative load and the genetic diversity of Campylobacter spp. in different age groups of cattle from dairy farms in the central part of Lithuania.

\section{Materials and methods}

The research program for this study was approved by the Committee of the Veterinary Medicine and Zootechnics Sciences Areas (Protocol No.04/2010).

\section{Study design}

Three dairy cattle farms (I, II, and III) with animal number on farms varying from 820 up to 1500 were included in the study. Rectal content grab samples were collected from May to August in 2012. All animals included in the study were clinically healthy. For each farm, animals were divided into three groups, depending on the age: calves (1-3 month of age), heifers (4-12 month of age) and cows (13-84 month of age). Altogether, 59 calves (farm I - 19, farm II - 20, farm II - 20), 80 heifers (farm I - 20, farm II - 40, farm II - 20) and 61 cow (farm I 21, farm II - 20, farm II - 20) faecal samples were collected and tested for Campylobacter spp. For faecal sampling all farms were visited twice. On all farms, milking cows were housed inside throughout the year without access to pastures. Heifers were kept in groups of 10-20 animals per group and had access to outside areas in all farms. Calves ware kept in individual pens until the age of 5-15 days. After that, they were regrouped into groups of 10-15 animals until the age of 3 months. In contrast, calves at farm II were housed individually in pens for a 3 month period.

\section{Campylobacter spp. isolation, identification and quantification}

All samples were analysed individually. The samples were transferred to the laboratory in a refrigerated bag at $4^{\circ} \mathrm{C}$ and analysed immediately. Thermophilic Campylobacter spp. were isolated by both, direct plating on modified charcoal cefoperazone deoxycholate agar (mCCDA; Liolfilchem, Roseto degli Abruzzi, Italy), and selective enrichment in Bolton broth (Oxoid, Basingstoke, UK).

To detect campylobacters, portions (10 g) of each faecal sample were diluted with $90 \mathrm{ml}$ buffered peptone water (BPW; Oxoid) and mixed for $1 \mathrm{~min}$. For the enumeration of Campylobacter spp., serial 10-fold dilutions of faecal samples were plated directly onto mCCDA. Inoculated mCCDA plates were incubated microaerobically ( $85 \%$ nitrogen, $10 \%$ carbon dioxide and $5 \%$ oxygen) generated by Campygen (Oxoid) at $37^{\circ} \mathrm{C}$ for $48 \mathrm{~h}$. After incubation, colonies of campylobacters were counted on the basis of colony morphology and typical cell motility (phase-contrast microscopy). Oxidase test was used for primary confirmation of isolated Campylobacter spp. Five putative Campylobacter spp. colonies (per faecal sample) were subcultured onto blood agar plates (Blood Agar Base No. 2; Liolfilchem) supplemented with 5\% Laked horse blood and incubated at $37^{\circ} \mathrm{C}$ for $48 \mathrm{~h}$ under microaerobic conditions as described above. The purified isolates were subsequently stored at $-80^{\circ} \mathrm{C}$ in $\mathrm{BHI}$ broth (BHI; Oxoid) with 30\% glycerol (Stanlab, Poland).

A selective enrichment procedure was performed for detect of low numbers of thermophilic campylobacters in faecal samples. For this procedure, $1 \mathrm{~g}$ faeces was placed in a tube containing a $9 \mathrm{ml}$ Bolton selective enrichment broth (Oxoid) with Bolton broth selective supplement (Oxoid) and 5\% Laked horse blood (Oxoid). Enrichment tubes were incubated microaerobically at $42^{\circ} \mathrm{C}$ for $24 \mathrm{~h}$. After incubation, $10 \mu \mathrm{l}$ of the enrichment culture was streaked onto mCCDA plates. The identification and purification of Campylobacter isolates was further performed as described above. Campylobacter counts (cfu/g) of the faecal cattle samples were calculated according to ISO 10272-2:2006.

Campylobacter spp. DNA was extracted from presumptive colonies using the boiling method. Briefly, after growing the bacteria on blood agar plates, a loopful $(\sim 10 \mu \mathrm{l})$ of bacterial culture was taken from two days incubated blood agar plates supplemented with 5\% horse blood. The cells were transferred to an Eppendorf tube containing $500 \mu \mathrm{l}$ distilled water. The samples were vortexed. The suspension was heated at $100^{\circ} \mathrm{C}$ for $10 \mathrm{~min}$ and then centrifuged for $5 \mathrm{~min}$ at $14000 \mathrm{rpm}$. The supernatant was transferred into a new tube. Extracted DNA was used immediately for PCR amplification or stored at $-20^{\circ} \mathrm{C}$ until examination.

Campylobacter isolates were identified to the species level by a multiplex PCR assay described by Wang et al. 
(2002) with minor modifications. Campylobacter spp. (23S rRNA) C. jejuni (hipO), C. coli (glyA), C. lari (glyA), C. upsaliensis (glyA) and C. fetus subsp. fetus (sapB2) primer mix was used to identify the species [24].

Each PCR mixture contained $2.0 \mu \mathrm{l}$ of a $2 \mathrm{mM}$ deoxynucleoside triphosphate mixture, $2.5 \mu \mathrm{l}$ of $10 \mathrm{X}$ reaction buffer, $2.5 \mu \mathrm{l}$ of $25 \mathrm{mM} \mathrm{MgCl} 2,0.25 \mu \mathrm{l}$ of HotStart Taq DNA polymerase (MBI, Fermentas), $1 \mu \mathrm{l}$ of a $100 \mu \mathrm{M}$ primer mixture containing $23 \mathrm{~S}$ rRNA $(0.5 \mu \mathrm{M})$, hipO $(1 \mu \mathrm{M})$ and glyA $(0.5 \mu \mathrm{M})$ primers, $1 \mu \mathrm{l}$ of chromosomal DNA, and MiliQ water to a final volume of $25 \mu$ l. DNA amplification was carried out in a thermocycler using an initial denaturation step at $95^{\circ} \mathrm{C}$ for 6 min followed by 30 cycles of amplification (denaturation at $0.5 \mathrm{~min}$, annealing at $53^{\circ} \mathrm{C}$ for $0.5 \mathrm{~min}$, and extension at $72^{\circ} \mathrm{C}$ for $0.5 \mathrm{~min}$ ), ending with a final extension at $72^{\circ} \mathrm{C}$ for $7 \mathrm{~min}$. Each PCR product $(11 \mu \mathrm{l})$ was loaded into a $1.3 \%$ TopVisionLM GQ Agarose (MBI, Fermentas) gel wells containing $0.05 \mu \mathrm{l} / \mathrm{ml}$ of ethidium bromide solution and analyzed by gel electrophoresis. The gel was visualized on an UV board. The GeneRulerTM 100 bp DNA Ladder (MBI, Fermentas) was used as the molecular size marker.

\section{Genotyping of $C$. jejuni isolates}

C. jejuni isolates were selected according to farms and dairy cattle age. Overall 49 isolates were genotyped. After DNA extraction, flaA PCR-RFLP genotyping was performed on $C$. jejuni isolates according to the technique described previously [25]. Primers A1 5'-GGA TTT CGT ATT AAC ACA AAT GGT GC-3' and A2 5'-CTG TAG TAA TCT TAA AAC ATT TTG-3' were used to amplify the flaA gene from $C$. jejuni. The restriction enzyme HpyF31 (DdeI) (ThermoScientific, Waltham, US) was used for the RFLP analysis of the PCR product. The GeneRuler 100 bp plus DNA Ladder (ThermoScientific) was used as the molecular size marker. flaA types were assigned manually by comparing band positions.

\section{Statistical analysis}

Obtained data were analysed with SPSS 16.0 software with analysis of variance using the General linear model (GLM) procedure. A chi-squared $\left(\chi^{2}\right)$ test was used to compare the prevalence of Campylobacter from different farms or cattle age groups. Differences were considered statistically significant when $\mathrm{p} \leq 0.05$. The Simpson's index of diversity (D) was used to determine the genetic diversity of C. jejuni genotypes [26]:

$$
D=1-\frac{1}{N(N-1)} \sum_{j=1}^{s} n j(n j-1)
$$

$\mathrm{N}$ - number of isolates tested;

$\mathrm{S}$ - number of different genotypes;

$\mathrm{nj}$ - number of isolates belonging to type $\mathrm{j}$.

\section{Results}

\section{Campylobacter prevalence}

In this study, Campylobacter spp. were isolated from $157(78.5 \%)$ out of 200 faecal samples collected from three dairy cattle farms located in the central part of Lithuania (Table 1). Of these, 14 samples (8.9\%) were confirmed positive only after an enrichment step, whereas 143 samples (91.1\%) were confirmed positive after direct plating, suggesting a high number of Campylobacter in dairy cattle faeces. Dairy cattle herds of all three farms were Campylobacter spp. positive, with a prevalence ranging from $75 \%$ (farm I), 77.5\% (farm II) to $83.3 \%$ (farm III). The individual farm had no significant influence $(\mathrm{p}<$ 0.05 ) on the prevalence of this pathogen. When combining data of all three farms, the prevalence of Campylobacter spp. was highest among calves (86.5\%) and heifers (86.2\%),

Table 1 Campylobacter spp. prevalence, number and species distribution in the dairy cattle farms

\begin{tabular}{|c|c|c|c|c|c|c|c|c|}
\hline \multirow[t]{2}{*}{ Source } & \multirow{2}{*}{$\begin{array}{l}\text { Age } \\
\text { group }\end{array}$} & \multirow{2}{*}{$\begin{array}{l}\text { Prevalence (\%) } \\
\text { (pos. samples/ } \\
\text { no. of samples } \\
\text { tested) }\end{array}$} & \multirow{2}{*}{$\begin{array}{l}\text { Quant. load } \\
\left.\text { ( } \log _{10} \mathrm{cfu} / \mathrm{g}\right) \\
\text { (Mean } \pm \text { SD) }\end{array}$} & \multicolumn{5}{|c|}{ Positive samples No./\% } \\
\hline & & & & C. jejuni & C. coli & C. Iari & C. fetus subsp. fetus & C. spp. \\
\hline \multirow[t]{3}{*}{ Farm I } & Calves & $89.4^{\mathrm{a}^{*}}(17 / 19)$ & $5.62^{a^{*}} \pm 0.95$ & $7 / 41.2$ & $4 / 23.5$ & - & 4/23.5 & 3/17.6 \\
\hline & Heifers & $85^{b}(17 / 20)$ & $4.37^{b} \pm 0.54$ & $13 / 76.5$ & $1 / 5.9$ & $2 / 11.8$ & 3/17.6 & $1 / 5.9$ \\
\hline & Cows & $53.2^{c}(11 / 21)$ & $3.55^{c} \pm 0.92$ & $11 / 100.0$ & $3 / 27.3$ & - & - & - \\
\hline \multirow[t]{3}{*}{ Farm ॥ } & Calves & $70^{a}(14 / 20)$ & $4.64^{\mathrm{a}} \pm 1.29$ & $6 / 42.9$ & $1 / 7.1$ & $1 / 7.1$ & $4 / 28.6$ & $3 / 21.4$ \\
\hline & Heifers & $85^{\mathrm{b}}(34 / 40)$ & $4.48^{b} \pm 0.69$ & $21 / 61.8$ & $13 / 38.2$ & $2 / 5.9$ & $1 / 2.9$ & $5 / 14.7$ \\
\hline & Cows & $70^{a}(14 / 20)$ & $4.17^{c} \pm 0.54$ & $7 / 50.0$ & $5 / 35.7$ & - & $6 / 42.9$ & $1 / 7.1$ \\
\hline \multirow[t]{3}{*}{ Farm III } & Calves & $100^{a}(20 / 20)$ & $5.49^{\mathrm{a}} \pm 0.90$ & $14 / 70.0$ & $5 / 25.0$ & - & - & $5 / 25.0$ \\
\hline & Heifers & $90^{b}(18 / 20)$ & $4.82^{b} \pm 0.83$ & $17 / 94.4$ & $5 / 27.8$ & - & - & 3/16.7 \\
\hline & Cows & $60^{c}(12 / 20)$ & $3.29^{c} \pm 0.44$ & $8 / 66.7$ & $1 / 8.3$ & - & $1 / 8.3$ & $5 / 41.7$ \\
\hline Total & & $78.5 \%(157 / 200)$ & $4.5 \pm 1.03$ & & & & & \\
\hline
\end{tabular}

*-Numbers followed by a different letter in the column are significantly different $(p<0.05)$ for different age groups the individual farm. 
whereas only $60.6 \%$ of dairy cow samples contained campylobacters. The highest Campylobacter spp. prevalence was found in calves faecal samples collected at the farms I and III, with $89.4 \%$ and $100 \%$, respectively. However, differently from farms I and III, heifers from the farm II were more frequently $(\mathrm{p}<0.05)$ infected than calves and cows. Campylobacter spp. bacteria were equally prevalent among calves and cows at farm II ( $\mathrm{p}>0.05)$.

Three Campylobacter species (C. jejuni, C. coli, C. fetus subsp. fetus) were found in samples collected from all sampled farms (Table 1), whereas C. lari species was detected in faecal samples collected at the farms I and II. The most prevalent species was $C$. jejuni (66.2\%), followed by C. coli (24.2\%). However, more than one Campylobacter spp. species was found in $21.7 \%$ of samples.

\section{Quantitative load of campylobacter}

The average count of Campylobacter spp. detectable in faeces samples was $4.5 \log _{10} \mathrm{cfu} / \mathrm{g}$ and numbers of bacteria in the faecal samples were not significantly different in all three farms $(p>0.05)$ (Table 1). Cattle age is an important factor influencing the number of campylobacters in faecal samples, as significant differences were found among all three cattle age groups $(\mathrm{p}<0.05)$. The highest numbers of Campylobacter spp. were found in faecal samples of calves (average $5.3 \quad \log _{10} \mathrm{cfu} / \mathrm{g}$ ), whereas cow samples harboured the lowest number of Campylobacter spp. (average $3.7 \log _{10} \mathrm{cfu} / \mathrm{g}$ ).

\section{Genotype diversity of $C$. jejuni isolates}

The flaA PCR-RFLP typing of 49 C. jejuni isolates resulted in 19 different flaA types (Table 2). Genotypes III, VI and XVII were found in samples of all three farms. Genotype III was dominant throughout all three dairy cattle farms. C. jejuni genotype I was dominant in calves samples whereas genotype III in young cattle samples, respectively. In addition, genotyping results revealed that several genotypes co-existed in each farm. Several genotypes were specific for an individual cattle age group (Table 2). Only one genotype (genotype V) was identified among all cattle age groups samples collected at the farm II. Genotype VII was dominant in cow samples. The highest diversity of $C$. jejuni genotypes was found at farm II $(D=0.92)$, whereas the lowest diversity was detectable at farm III $(\mathrm{D}=0.75)$ (Table 2). Isolates from cows samples showed the highest genetic diversity $(D=0.93)$, while the lowest diversity of the genotypes was identified among isolates from calves $(D=0.76)$.

\section{Discussion}

To our knowledge, this is the first study investigating the Campylobacter prevalence and quantitative load in dairy cattle in the Baltic States. Recent studies have shown that the contribution of non-poultry associated
Table 2 Distribution and diversity of C. jejuni flaA genotypes among different farms and cattle age groups

\begin{tabular}{|c|c|c|c|c|}
\hline \multirow[t]{2}{*}{ flaA types } & \multirow{2}{*}{$\begin{array}{l}\text { Absolute } \\
\text { no. of } \\
\text { isolates } \\
\text { per flaA } \\
\text { type }\end{array}$} & \multicolumn{3}{|c|}{ No. of isolates per flaA type } \\
\hline & & Farm I & Farm II & Farm III \\
\hline 1 & 9 & - & - & $7 A^{*} ; 2 B$ \\
\hline$\|$ & 4 & $3 B$ & $1 C$ & - \\
\hline III & 9 & $1 \mathrm{~A} ; 3 \mathrm{~B}$ & $2 B$ & $1 \mathrm{~A} ; 2 \mathrm{~B}$ \\
\hline IV & 1 & $1 C$ & - & - \\
\hline V & 4 & - & $1 \mathrm{~A} ; 2 \mathrm{~B} ; 1 \mathrm{C}$ & - \\
\hline $\mathrm{VI}$ & 3 & $1 \mathrm{~A}$ & $1 \mathrm{~B}$ & $1 \mathrm{~B}$ \\
\hline VII & 3 & - & - & $3 C$ \\
\hline VIII & 1 & - & $1 \mathrm{H}$ & - \\
\hline IX & 1 & $1 \mathrm{~B}$ & - & - \\
\hline$x$ & 1 & - & $1 \mathrm{~B}$ & - \\
\hline$X I$ & 1 & 1B & - & - \\
\hline$X \|$ & 1 & - & $1 C$ & - \\
\hline XIII & 2 & $1 \mathrm{~A}$ & - & $1 \mathrm{~A}$ \\
\hline XIV & 1 & - & - & $1 C$ \\
\hline$X V$ & 1 & - & $1 \mathrm{~B}$ & - \\
\hline$X V I$ & 1 & $1 C$ & - & - \\
\hline$X V \|$ & 4 & $2 B$ & $1 \mathrm{~B}$ & $1 C$ \\
\hline$X V I I I$ & 1 & - & 1B & - \\
\hline XIX & 1 & $1 \mathrm{~A}$ & - & - \\
\hline Total & 49 & 16 & 14 & 19 \\
\hline Simpson's Index (D) & & 0.91 & 0.92 & 0.75 \\
\hline
\end{tabular}

*Source of isolate: A - calves; B - heifers; C - cows.

Campylobacter strains to human campylobacteriosis is considerable $[8,27]$.

Despite the fact that Campylobacter is common in cattle herds, our study revealed a very high prevalence of these bacteria (average 78.5\%) in all 3 farms. Most other comparable studies reported prevalences between $5 \%$ and $67.1 \%$ [10-14,18,22,23,28-32]. Since these studies vary in sampling design, culture methods and conditions, a direct comparison of the results is difficult. However, our data contribute to previous discussions that cattle are significant reservoirs for Campylobacter spp. and could be a source of infection for other animals and humans [5,14]. There are studies describing transmission of campylobacters from cattle to poultry production chain. The significance of Campylobacter colonization of cattle are related not only to the potential for contamination of milk at the farm and the carcass at slaughter, but also surface and sub-surface water. In addition, several studies have found the presence of cattle, on broiler farms is associated with increased risk of infection in broiler flocks [6,21]. 
Results of several studies are contradictory, regarding the effect of age on the prevalence of Campylobacter in dairy cow farms. Our study showed that the cattle age significantly influences the prevalence of Campylobacter spp. $(\mathrm{p}<0.05)$ : the highest prevalence was observed in the calve groups in comparison to milking cow groups in farms I and III then animals are kept in groups of about 10-20. Similarly, former studies concluded that calves became colonized with Campylobacter within 4 days, with maximal Campylobacter shedding occurring at 1-2 months of age with prevalences of up to 42.1$46 \%$, while Campylobacter prevalences among older cows were significantly lower 9.2-28.5\% [12,14]. However, a more recent study [15] argued that dairy cattle age did not influence the prevalence of campylobacters in cattle faeces and Campylobacter prevalence between age groups ranged from $35 \%$ in animals above 60 months of age to $50 \%$ in those below 30 months. However, in this study the difference in prevalence between age groups was not significant. It should be mentioned that the prevalence of campylobacters among calves at the farm II was significantly lower in comparison to the prevalence among the corresponding age group calves at the farms I and III. This could be explained by different housing systems, since calves (also heifers and milking cows) in farm I and III were kept in groups of 10-20 animals, whereas calves at farm II were kept individually. One infected calve can contaminate the environment what leads to a quick transmission of campylobacters among calves of the same group [33].

Our study showed that $C$. jejuni was the dominant species in the tested samples, followed by $C$. coli. This is in accordance with other studies, which describe $C$. jejuni as the dominant Campylobacter species in cattle intestines $[11,28]$. However dominance of $C$. jejuni can differ at the broad range as Wesley et al. (2000) and Nielsen (2002) have reported prevalence of C. jejuni from $7 \%$ to $38 \%$ in dairy herds, which are at least twice lower in comparison to $66.2 \%$ prevalence revealed by our study. So we could speculate that dairy cattle play a significant role in $C$. jejuni epidemiology (responsible for $90 \%$ of human campylobacteriosis cases) as an important host of $C$. jejuni [3]. In addition, our study showed that cattle age is a significant risk factor for quantitative load of Campylobacter spp. Calves showed the highest numbers of Campylobacter in faeces, followed by heifers in all three farms. Cows had the lowest Campylobacter load in faeces. This is in agreement with other studies, demonstrating a similar dependence on higher concentrations in younger animals $[14,34]$. Overall, our quantitative data $\left(4.5 \log _{10} \mathrm{cfu} / \mathrm{g}\right)$ are comparable to previously published results, showing concentrations of 3.7 $\log _{10} \mathrm{cfu} / \mathrm{g}$ [14] and $4.4 \log _{10} \mathrm{cfu} / \mathrm{g}$ [32].

By applying the flaA PCR-RFLP method, which is widely used for genotyping of campylobacters, a high strain diversity was identified in the $C$. jejuni strains isolated at three dairy cow farms (Table 2). Multiple genotypes on the same farm may be related to multiple sources of infection or to a persistent infection leading to genetic variations within the $C$. jejuni population. Oporto et al. (2007) found a similarly high C. jejuni genetic diversity in dairy cattle (12 flaA types from 43 isolates) using the flaA PCR-RFLP method. Similarly, nine to 35 flaA-types were identified among cattle isolates in other studies $[35,36]$. In conclusion, although the overall results suggest that some genotypes exist in all dairy cattle farms, more than half of the genotypes in each farm were specific to the individual farm. This may be due to the fact that the geographical location has an influence on $C$. jejuni genetic diversity.

\section{Conclusions}

This study revealed a high prevalence and quantitative load of Campylobacter spp. in calves, heifers and milking cows at the three dairy farms, supporting the significance of cattle as a potential reservoir of transmission of Campylobacter spp. to humans. Despite the fact that age is the significant factor influencing the prevalence of campylobacters among calves, heifers and milking cows, our finding suggest that healthy dairy cattle of any age group can play a significant role in the contamination of the environment and the possible entrance of Campylobacter spp. into the food chain. Several different $C$. jejuni genotypes observed in each farm indicate multiple pathways involved into colonisation of dairy herds by Campylobacter spp. Further studies are needed to investigate the entrance pathways of Campylobacter into the herds which could lead to the development of specific measures to reduce colonisation of cattle with Campylobacter spp.

\section{Competing interests}

The authors declare that they have no competing interests.

\section{Authors' contributions}

SR collected and analysed the data, did the literature review and drafted the manuscript. AR, AM and ET assisted with data collection and testing. TA took part in the writing. MM generated the study design and revised the manuscript. All authors read and approved the final manuscript.

\section{Acknowledgements}

This research was funded by a grant (No. SVE 05/2011) from the Research Council of Lithuania.

\section{Author details}

${ }^{1}$ Department of Food Safety and Quality, Faculty of Veterinary Medicine, Veterinary Academy, Lithuanian University of Health Sciences, Tilzes 18, Kaunas LT-47181, Lithuania. ${ }^{2}$ Clinic of Children Diseases, Medicine Academy, Lithuanian University of Health Sciences, A. Mickeviciaus 9, Kaunas LT-44307, Lithuania. ${ }^{3}$ Department of Infectious Diseases, Faculty of Veterinary Medicine, Veterinary Academy, Lithuanian University of Health Sciences, Tilzes 18, Kaunas LT-47181, Lithuania. ${ }^{4}$ Institute of Food Hygiene, Freie Universität Berlin, Königsweg 69, Berlin 14163, Germany.

Received: 2 September 2013 Accepted: 19 November 2013

Published: 5 December 2013 


\section{References}

1. European Food Safety Authority (EFSA): The European union summary report on trends and sources of zoonoses, zoonotic agents and food-borne outbreaks in 2009. EFSA Journal 2011, 9:2090.

2. World Health Organization (WHO): The increasing incidence of human campylobacteriosis. Report and proceedings of a WHO consultation of experts. Copenhagen, Denmark; 2001. http://whqlibdoc.who.int/hq/2001/ who_cds_csr_aph_2001.7.pdf.

3. European Food Safety Authority (EFSA): The European union summary report on trends and sources of zoonoses, zoonotic agents and food-borne outbreaks in the European union in 2010. EFSA Journal 2012, 10:2597.

4. Moore JE, Corcoran D, Dooley JS, Fanning S, Lucey B, Matsuda M, McDowell DA, Mégraud F, Millar BC, O'Mahony R, O'Riordan L, O'Rourke M, Rao JR, Rooney PJ, Sails A, Whyte P: Campylobacter. Vet Res 2005, 36:351-382.

5. Kärenlampi R, Rautelin H, Hänninen ML: Longitudinal study of Finnish Campylobacter jejuni and C. coli isolates from humans, using multilocus sequence typing, including comparison with epidemiological data and isolates from poultry and cattle. Appl Environ Microbiol 2007, 73:148-155.

6. Stanley K, Jones K: Cattle and sheep farms as reservoirs of Campylobacter. J Appl Microbiol 2003, 94:104-113.

7. Sheppard SK, Dallas JF, Strachan NJ, MacRae M, McCarthy ND, Wilson DJ, Gormley FJ, Falush D, Ogden ID, Maiden MCJ, Forbes KJ: Campylobacter genotyping to determine the source of human infection. Clin Infect Dis 2009, 48:1072-1078.

8. Wilson DJ, Gabriel E, Leatherbarrow AJH, Cheesbrough J, Gee S, Bolton E, Fox A, Fearnhead P, Hart CA, Diggle PJ: Tracing the source of campylobacteriosis. PLoS Genet 2008, 4:e1000203.

9. Besser TE, LeJeune JT, Rice DH, Berg J, Stilborn RP, Kaya K, Bae W, Hancock DD: Increasing prevalence of Campylobacter jejuni in feedlot cattle through the feeding period. Appl Environ Microbiol 2005, 71:5752-5758.

10. Milnes AS, Stewart I, Clifton-Hadley FA, Davies RH, Newell DG, Sayers AR, Cheasty T, Cassar C, Ridley A, Cook AJC, Evans SJ, Teale CJ, Smith RP, McNally A, Toszeghy M, Futter R, Kay A, Paiba GA: Intestinal carriage of verocytotoxigenic Escherichia coli 0157, Salmonella, thermophilic Campylobacter and Yersinia enterocolitica, in cattle, sheep and pigs at slaughter in Great Britain during 2003. Epidemiol Infect 2008, 136:739-751.

11. Wesley IV, Wells SJ, Harmon KM, Green A, Schroeder- Tucker L, Glover M, Siddique I: Fecal shedding of Campylobacter and Arcobacter spp. in dairy cattle. Appl Environ Microbiol 2000, 66:1994-2000.

12. Johnsen G, Zimmerman K, Lindstedt BA, Vardund T, Herikstad H, Kapperud G: Intestinal carriage of Campylobacter jejuni and Campylobacter coli among cattle from south-western Norway and comparative genotyping of bovine and human isolates by amplified-fragment length polymorphism. Acta Vet Scand 2006, 48:4.

13. Kwan PLS, Birtles A, Bolton FJ, French NP, Robinson SE, Newbold LS, Upton M, Fox AJ: Longitudinal study of the molecular epidemiology of Campylobacter jejuni in cattle on dairy farms. Appl Environ Microbiol 2008, 74:3626-3633.

14. Nielsen EM: Occurrence and strain diversity of thermophilic campylobacters in cattle of different age groups in dairy herds. Lett Appl Microbiol 2002, 35:85-89.

15. Lin J: Novel approaches for Campylobacter control in poultry. Foodborne Pathog Dis 2009, 6:755-765.

16. Wagenaar JA, Mevius DJ, Havelaar AH: Campylobacter in primary animal production and control strategies to reduce the burden of human campylobacteriosis. Rev Sci Tech Off Int Epiz 2006, 25:581-594.

17. Heuvelink AE, van Heerwaarden C, Zwartkruis-Nahuis A, Tilburg JJ, Bos MH, Heilmann FG, Hofhuis A, Hoekstra T, de Boer E: Two outbreaks of campylobacteriosis associated with the consumption of raw cows' milk. Int J Food Microbiol 2009, 134:70-74.

18. Hakkinen M, Heiska H, Hänninen ML: Prevalence of Campylobacter spp. in cattle in Finland and antimicrobial susceptibilities of bovine Campylobacter jejuni strains. Appl Environ Microbiol 2007, 73:3232-3238.

19. Devane ML, Nicol C, Ball A, Klena JD, Scholes P, Hudson JA, Baker MG, Gilpin BJ, Garrett N, Savill MG: The occurrence of Campylobacter subtypes in environmental reservoirs and potential transmission routes. J App/ Microbiol 2005, 98:980-990.

20. Garrett N, Devane ML, Hudson JA, Nicol C, Ball A, Klena JD, Scholes P, Baker MG Gilpin BJ, Savill MG: Statistical comparison of Campylobacter jejuni subtypes from human cases and environmental sources. J App/ Microbiol 2007, 103:2113-2121.
21. Minihan D, Whyte P, O'Mahony M, Fanning S, McGill K, Collins JD: Campylobacter spp. in Irish feedlot cattle: a longitudinal study involving pre-harvest and harvest phases of the food chain. J Vet Med B Infect Dis Vet Public Health 2004, 51:28-33.

22. Sasaki Y, Murakami M, Haruna M, Maruyama N, Mori T, Ito K, Yamada Y Prevalence and characterization of foodborne pathogens in dairy cattle in the eastern part of Japan. J Vet Med Sci 2013, 75:543-546.

23. Sato K, Bartlett PC, Kaneene JB, Downes FP: Comparison of prevalence and antimicrobial susceptibilities of Campylobacter spp. isolates from organic and conventional dairy herds in Wisconsin. Appl Environ Microbiol 2004, 70:1442-1447.

24. Wang G, Clark CG, Taylor TM, Pucknell C, Barton C, Price L, Woodward DL, Rodgers FG: Colony multiplex PCR assay for identification and differentiation of Campylobacter jejuni, C. coli, C. Iari, C. upsaliensis, and C. fetus subsp. fetus. J Clin Microbiol 2002, 40:4744-4747.

25. Harrington CS, Moran L, Ridley AM, Newell DG, Madden RH: Inter-laboratory evaluation of three flagellin PCR/RFLP methods for typing Campylobacter jejuni and C. coli: the CAMPYNET experience. J Appl Microbiol 2003, 95:1321-1333.

26. Hunter P: Reproducibility and indices of discriminatory power of microbial typing methods. J Clin Microbiol 1990, 28:1903-1905.

27. Ragimbeau C, Schneider F, Losch S, Even J, Mossong J: Multilocus sequence typing, pulsed-field gel electrophoresis, and fla short variable region typing of clonal complexes of Campylobacter jejuni strains of human, bovine, and poultry origins in Luxembourg. Appl Environ Microbiol 2008, 74:7715-7722.

28. Fernandez $\mathrm{H}$, Hitschfeld M: Occurrence of Campylobacter jejuni and Campylobacter coli and their biotypes in beef and dairy cattle from the south of Chile. Braz J Microbiol 2009, 40:450-454.

29. Hakkinen M, Hänninen ML: Shedding of Campylobacter spp. in Finnish cattle on dairy farms. J App/ Microbiol 2009, 107:898-905.

30. Hoar BR, Atwill ER, Elmi C, Farver TB: An examination of risk factors associated with beef cattle shedding pathogens of potential zoonotic concern. Epidemiol Infect 2001, 127:147-155.

31. Oporto B, Esteban Jl, Aduriz G, Juste RA, Hurtado A: Prevalence and strain diversity of thermophilic campylobacters in cattle, sheep and swine farms. J App Microbiol 2007, 103:977-984.

32. Rotariu O, Dallas JF, Ogden ID, MacRae M, Sheppard SK, Maiden MC, Gormley FJ, Forbes KJ, Strachan NJ: Spatiotemporal homogeneity of Campylobacter subtypes from cattle and sheep across northeastern and southwestern Scotland. Appl Environ Microbiol 2009, 75:6275-6281.

33. Rapp D, Ross CM, Pleydell EJ, Muirhead RW: Differences in the fecal concentrations and genetic diversities of Campylobacter jejuni populations among individual cows in two dairy herds. Appl Environ Microbiol 2012, 78:7564-7571.

34. Stanley KN, Wallace JS, Jones K: Thermophilic campylobacters in dairy slurries of Lancashire farms: seasonal effects of storage and land application. J Appl Microbiol 1998, 85:405-409.

35. Fitzgerald C, Stanley K, Andrew S, Jones K: Use of pulsed-field gel electrophoresis and flagellin gene typing in identifying clonal groups of Campylobacter jejuni and Campylobacter coli in farm and clinical environments. Appl Environ Microbiol 2001, 67:1429-1436.

36. Madden RH, Moran L, Scates P: Frequency of occurrence of Campylobacter spp. in red meats and poultry in Northern Ireland and their subsequent subtyping using polymerase chain reaction-restriction fragment length polymorphism and the random amplified polymorphic DNA method. J Appl Microbiol 1998, 84:703-708.

doi:10.1186/1751-0147-55-87

Cite this article as: Ramonaite et al:: Prevalence, quantitative load and genetic diversity of Campylobacter spp. in dairy cattle herds in Lithuania. Acta Veterinaria Scandinavica 2013 55:87. 